\title{
STAKEHOLDERS' INVOLVEMENT AND THEIR PERCEPTIONS IN SUPPORTING COMMUNITY-BASED ECOTOURISM IN MIN HOUSE CAMP, KUBANG KERIAN
}

\author{
Siti Mariam Mellisa Abdullah (PhD) ${ }^{1}$ \\ Department of Economics, Faculty of Economics and Management, \\ University Putra Malaysia. \\ (Email: lissa88.ml@gmail.com) \\ Mohd Shahwahid Haji Othman ${ }^{2}$ \\ Professor, Department of Economics, \\ Faculty of Economics and Management, \\ University Putra Malaysia. \\ (Email: mohdshahwahid@gmail.com) \\ Fatin Farazh Ya'acob $(\mathbf{P h D})^{3}$ \\ Department of Economics, Faculty of Economics and Management, \\ University Putra Malaysia. \\ (Email: farazh.whg@gmail.com)
}

Received date: 27-06-2019

Revised date: 13-08-2019

Accepted date: 15-09-2019

Published date: 15-09-2019

To cite this document: Abdullah, S. M. M., Haji Othman, M. S., \& Ya'acob, F. F. (2019). Stakeholders' Involvement and Their Perceptions in Supporting Community-Based Ecotourism in Min Hoise Camp, Kubang Kerian. Journal of Tourism, Hospitality and Environment Management, 4(16), 70-83.

DOI: $10.35631 / \mathrm{JTHEM} .416006$

Abstract: One of the new forms of ecotourism product is community-based ecotourism (CBE) which is involved and managed locally by the communities in its development and management, and substantial benefits remain within the community. Stakeholders involvement in CBE development plays an important role in the success and sustainable development in rural Min House Camp, Kubang Kerian Kelantan. Stakeholders such as governments, private enterprise, local communities, institutions, non-governmental organization and volunteer tourist involved in the planning and decision-making process of the rural ecotourism management and conservation. This study has been conducted in Min House Camp which located at the village of Kampung Pulau that involved different stakeholders using partial least square structural equation modeling method. The findings show stakeholders involvements have significantly influenced on perceived benefit and perceived cost. The business operator should understand the importance of perceived 
benefits and costs of community-based ecotourism as this construct has a strong influence to support community-based ecotourism development in rural MHC. This study provides useful information for the policymaker, government, and tourism operators to enhance greater stakeholder participation in developing and sustaining community-based ecotourism.

Keywords: Ecotourism; Community-Based Ecotourism; Stakeholders Involvement; Sustainable Development; Partial Least Square Structural Equation Modelling

\section{Introduction}

The viability of community-based tourism is depending on how well balancing relationship among local community, governments, non-governmental organization, institutions, private enterprises and tourists (Zhang et al., 2006) to cope with new expectations (The Mountain Institute, 2000). Community-based ecotourism (CBE) is a panacea of community development that help to empower the rural communities to manage tourism resources and participate the local community in the tourism services. Developed economies such as Canada, New Zealand and Australia as well as developing economies like Vietnam, Indonesia, China and Malaysia has been applied for CBE (Canada Universities Consortium,2000). Various literature shows CBE project mostly initiated and operated by outsider which are non-governmental organizations (Ashley and Garland,1994). and not by the local community, particularly case in Malaysia. Stakeholders involvement and support for CBE is important for sustainable tourism development that lead to more fair distribution of the benefits, discourage undemocratic decision-making and satisfy the local community needs in different ways (Aref and Redzuan, 2008).

Having CBE can be seen as one of the potential opportunities to be developed. There are isolated sites where CBE is successful in Kelantan. Personal communication with the Director of the Office of the Ministry of Tourism, Art and Cultures for the State of Kelantan (MOTAC) mentioned that $\mathrm{MHC}$ is one of the best practicing setup operating CBE that is officially registered in one of the villages in Kubang Kerian, Kelantan. Therefore, this study chose MHC as a case study of best practiced CBE. Why is MHC the best practiced and successful? Firstly, MHC is a practicing CBE entrepreneur in Kelantan that is managed by local entrepreneurs who involves the local community that lives in it. Furthermore, this CBE enterprise has received support from various stakeholders such as local communities, government, private enterprise, a local institution, non-governmental organisations and volunteer tourists. Having CBE business in MHC has created benefits for the locals in terms of job opportunities and income earning. Second, MHC has fully utilised the unique endowment available in Kelantan and offers various ecotourism attractions which have attracted many visitors including foreigners from all around the world. Third, it also incorporates conservation in its business where the education of nature and cultures is provided to the tourists. Apart from that, MHC has received awards from the Ministry of Tourism, Art and Culture (MOTAC) as a "Green Budget Hotel" and "Community-based Tourism" in Malaysia. It appears that CBE ala MHC has been successful because of the support from the stakeholder towards CBE development. This study is motivated by the need to understand what makes MHC a successful $\mathrm{CBE}$ operation rather than in trying to solve problems that it is facing. Therefore, it is important to understand the main stakeholders involved in ecotourism that contributes to the development and growth of CBE in MHC. 
Min House Camp (MHC) is based in Kampung Pulau, Kubang Kerian, Kelantan (on the edge of Kota Bharu) which focuses on ecotourism and agro-tourism. MHC is one of the CBE locations that is rich in natural flora and fauna, surrounded by lush green forests situated next to the Peng Datu River. MHC is one of the officially registered villages of Kelantan that offer more than 15 chalets, multipurpose halls, Trigona bee farm, a firefly garden, an organic farm, petting zoo and even water sports facilities such as kayaking, river bathing, fishing and clam digging.MHC in Kubang Kerian has offered various ecotourism activities that require participation from the local community whereas other places do not offer. MHC has attracted many foreign tourists from all over the world due to its unique culture and different environment compared to other ecotourism in Kelantan. Hence MHC can be set as a benchmark for other rural communities to operate similar businesses. Using MHC as a model, interested local communities could be given the opportunity to hone their local entrepreneurship skills and set up their own small businesses as long as they can get the local communities living within or adjacent to the ecotourism sites to participate and involve in the tourism planning and management, offering natural and cultural activities, and receive support from various key stakeholders such as government, private enterprise, nongovernmental organizations, educational institutions, local communities and volunteers.

In the case of MHC, most of the stakeholders that supported the CBE development were involved and participating in the tourism management and conservation program. The definition of community in the context of this study refer to a group of individuals living or working within the same geographic area with some shared cultures or common interest. The positive attitudes come from the operator that is willing to share the benefit with the local communities. However, the local communities are willing to participate and offer the trade, involve in boat guide, food stall, stingless beehive supplier, and others. Most of the local communities in MHC generally perceive tourism activities positively, especially because of the economic benefits, including job opportunities and generated additional income. Socio-cultural aspects are generally perceived positively too, mainly because of enhanced local cultural and crafts activities. However, there are also some negative attitude as they see foreign visitor as intruding the village and this local people do not have entrepreneurship attitude as compared to other local communities that participate in ecotourism activities. The environmental component is often perceived by the local community in negative terms, due to some the costs brought on by tourism development like pollution, crowding, destruction of natural habitats, crime and others. Hence, some of the local communities does not actively participate in tourism activities as they do not see the value and benefit offered by CBE.Therefore, understanding stakeholders' involvement towards support for CBE projects will greatly contribute to the success and sustainability developments in MHC (Claiborne, 2010; Lepp, 2008).

\section{Literature Review}

In this study, stakeholders in tourism are considered as significant key players that influence the success or failure of tourism in a region, and their participation and involvement should take into consideration tourism planning and development. While numerous researchers have examined the determinants of residents' perceived impacts, limited research has been undertaken in Kelantan of understanding the stakeholders' involvement and perception in supporting CBE development. 


\section{Theoretical Framework}

The Social Exchange Theory (SET) has been applied in different fields of study, including anthropology, economics, psychology behaviour and social psychology. Notwithstanding, in tourism studies, some researchers applied the theoretical framework of SET in explaining the attitude of residents towards tourism development (Gursoy et al., 2002; Nunkoo et al., 2011). Here, those studies focused on how residents assess the benefits and costs of tourism development and also explained their support for future tourism development based on the evaluation of benefits and costs (Yoon et al., 2001).

According to Ap (1992), to sustain tourism in a community, certain exchanges must occur. He further highlights that participation by a community such as residents, civic leaders, and entrepreneurs in developing and attracting tourism to a community is generally driven by the desire by some members of a community to improve the economic and social conditions. Furthermore, Ap (1992) mentioned that residents evaluate tourism "regarding the expected benefits or costs acquired in return for the services they had offered". Thus, it is assumed that host residents seek tourism development for the communities in order to gain benefits from it without bearing undesirable costs and as a means to improve the community's overall well-being.

In a separate study, Yoon et al. (2001) investigated the attitudes of residents and the support for tourism development using a structural equation model (SEM). The study mentioned that residents are likely to support tourism development provided the perceived benefits outweigh the perceived costs. Their empirical results support economic and cultural impacts as having a positive relationship with the "overall tourism impact", while social and environmental impacts have negative effects on the "total impact of tourism". Overall, "the total impact of tourism" is positively associated with the "support for tourism development". Consequently, the residents were likely to support the development of tourism if they received more benefits associated with tourism.

The advantages of adopting SET are that it can accommodate clarification of both benefit and cost perceptions and can study relationships at the individual or collective level (Ap, 1992). SET offers the most suitable theoretical framework for this field of research. Furthermore, SET is adopted in the current study given it helps researchers explain both kinds of perceptions (benefit and cost), allows for examining relationships on both the individual and the collective level as well as help in predicting stakeholders' intention to support the development of CBE. Moreover, SET provides a suitable framework for examining stakeholders' perceptions and explaining how the exchange factors affect the results or outcomes of the exchange process.

\section{Stakeholders' Support for Community-based Ecotourism Development}

\section{Hypothetical Constructs}

\section{Stakeholders Involvement}

There are different groups of stakeholders that participate and involve in CBE activities since they have different opinions and desires regarding their regions ' development (Garrod, 2003).Few studies have only focus on the local community perspectives and support on ecotourism development (Jim and Xu, 2002; Lai and Nepal, 2006; Tsaur et al.,2006;Stem et al., 2003). For instance, local communities were ignored regularly and/or not even invited to get involved in 
making decision and manage the tourism resources. Current studies have emphasized the importance of stakeholders' participation in matters related to tourism development (Wanga et al.,2014; Saito and Ruhanen,2017). However, as suggested by Rasoolimanesh et al. (2017), the mediating role of participation by community among residents and supporting rural and urban tourist development. From the economic, social-cultural and environmental perspective study and in line with Rasoolimanesh et al. (2017) model, stakeholders involvement affects support of CBE development via mediation effect of perceived costs and perceived benefits. Those stakeholders that highly involve in CBE activities in the same way, would tends to support its development. Therefore, the following hypothesis are set up: -

H1: There is a direct relationship between stakeholders' involvement and perceived benefits in $\mathrm{CBE}$.

$\mathrm{H} 2$ : There is a direct relationship between stakeholders' involvement and perceived costs in CBE.

\section{Perceived Benefit and Cost of $\mathrm{CBE}$}

Residents ' conceptions of tourism's impacts are a critical predictor of their support for tourism development and sustainable development and management of tourism (Gursoy et al., 2002; Jaafar et al., 2015b; Nicholas et al., 2009). Sharpley and Telfer (2008) highlighted that residents would support for development of tourism based on their own belief of tourism's positive and negative impacts. Positive perceptions of community impact encourage residents to support tourism development, while the negative perceptions impacts cause them less support for development of tourism (Sharpley, 2014). This is supported by Nicholas et al., (2009) where residents perceived positively and negatively on the development of tourism will affect their participation in tourism and the sustainability of any development of tourism. Numerous studies using SET to know the effects of residents ' opinions on tourism development support and participation (Gursoy et al., 2002; Haobin et al., 2014; Látková and Vogt, 2012; Rasoolimanesh et al., 2015; Wang and Pfister, 2008). This theory shows residents that gain benefits of development of tourism with less costs lead them to exchange and interact with tourists and to support tourism development in their communities (Gursoy et al., 2002; Haobin et al.,2014; Rasoolimanesh et al., 2015). On the other hand, residents that suffer more due to tourism development would stop supporting any future involvement in the development of tourism (Nunkoo \& Ramkissoon, 2011).

H3: There is a direct relationship between stakeholders' perceived benefits and support for CBE development.

H4: There is a direct relationship between stakeholders' perceived costs and support for CBE development.

\section{Methodology}

\section{Data Collection Procedure}

A questionnaire was used in the quantitative study to measure positive perceptions ( 7 items) (Moswete, 2009), negative perceptions (6 items) (Moswete ,2009; Ko and Stewart, 2002; Tosun 2002; Almeida-García et al.,2016; Gursoy et al. 2002, Gursoy and Rutherford, 2004; Nunkoo and Ramkissoon, 2011a), stakeholders' participation (4 items) (Nicholas et al., 2009; Rasoolimanesh et al,2016; Rasoolimanesh et al.,2017; Jaafar et al., 2015a) and support for CBE development (5 items) Moswete, 2009). These statements were all adapted from previous studies. Questions have 
been answered using a 5-point Likert scale, with 1 indicate strongly disagree and 5 strongly agree). The study managed to get information for the owner of $\mathrm{MHC}$ regarding identification of multiple stakeholders that involved in CBE activities in MHC Kubang Kerian, Kelantan. The study's target population was restricted to stakeholders which are governments, private enterprise, local institutions, NGO, local communities and volunteer tourists living in Kelantan above 18 years old. The interview was conducted by trained enumerators for a period of 3 months (October to December 2017). For the survey, a purposive sampling technique was used to ensure proper representation from different stakeholders. These stakeholders were invited participate in the surveys through face-to-face session from six stakeholders' group. To reduce the involvement of referrals, they were explained the purpose of the research. From this survey, 20 responses were discarded due to large proportions of the questions are not being answered and 80 responses were non-responses. Therefore, 200 questionnaires out of 300 were usable questionnaires.

\section{Results and Analysis}

\section{Assessment of Measurement Model}

For this study, the assessment of the reflective measurement and structural model tested using Smart PLS 3.0 (Hair et al., 2017). This statistical program evaluates the psychometric properties of the measuring model and calculates the structural model parameters. In the first stage of analysis is the acceptability of the measurement models in supporting CBE context needed to be confirmed (Hair et al.,2014). measurement model assessment involves the assessment of the model's validity and reliability indicators (items). The measurement model applies in this study include four variables: stakeholders' involvement, positive perception, negative perception of stakeholders toward supporting CBE development in MHC, Kubang Kerian, Kelantan. Under the reflective measurement model, two types of convergent validity (CR) and discriminating validity are evaluated. Factor loading, and AVE are used to assess convergent validity (Hair et al, 2017). The results of indicator loadings, $\mathrm{CR}$ and $\mathrm{AVE}$ of the reflective constructs are shown in Table 1 below. As suggested by Hair et al., (2017), all the loadings which more than recommended value of 0.708 are retained. A loading of 0.4 implies that an item should be deemed for removal and a loading item of $0.4-0.7$ should be considered for removal if the CR and AVE above the threshold are increased (Chin, 2010; Hair et al., 2011).

Based on the result below, most of the indicator loading are higher than 0.708. Several indicators loaded between 0.4 and 0.7 , indicating that they could be considered for CR and AVE removal. The CR coefficient is also used to assess the reliability of the construct and should exceed 0.7 to determine the reliability of the construct. (Chin 2010; Hair et al.,2011). Table 3 shows that the CR is higher than 0.7 for all items in the measurement model. These results indicate the acceptable reliability of the measurement model.

To evaluate the convergent validity of the measurement model for this research, the AVE of the items should also be higher than 0.5 to be considered acceptable for convergent validity. (Chin 2010; Hair e al.,2011). Based on the result, all the constructs have met the threshold values/satisfactory values for CR and AVE, where all CRs are exceed than 0.7 and all AVEs are exceed than 0.5 (Hair et al., 2017). Therefore, it is concluded that at this first stage the constructs meet the requirement for reliability and convergent validity. Moreover, due to the CR and AVE are higher than the threshold, we concluded that it was unnecessary to remove indicators from 
measuring models with loading 0.4-0.7. Therefore, items SI2, SI24, PC5 with low loadings lower than 0.708 are maintain when the minimum of AVE result of 0.5 is achieved.

Table 1: Assessment Results of the Measurement Model

\begin{tabular}{|l|l|l|l|l|}
\hline Construct/Items & Items & Loadings & AVE & CR \\
\hline Stakeholder Involvement & SI1 & 0.837 & 0.545 & 0.826 \\
\hline & SI2 & 0.664 & & \\
\hline & SI3 & 0.744 & & \\
\hline & SI4 & 0.696 & & \\
\hline Perceived Benefit & PB1 & 0.885 & 0.775 & 0.960 \\
\hline & PB2 & 0.896 & & \\
\hline & PB3 & 0.877 & & \\
\hline & PB4 & 0.943 & & \\
\hline & PB5 & 0.848 & & \\
\hline & PB6 & 0.847 & & \\
\hline & PB7 & 0.862 & & \\
\hline Perceived Cost & PC1 & 0.728 & 0.603 & 0.899 \\
\hline & PC2 & 0.844 & & \\
\hline & PC3 & 0.772 & & \\
\hline & PC4 & 0.868 & & \\
\hline & PC5 & 0.607 & & \\
\hline & PC6 & 0.799 & & \\
\hline Support CBE Development & SUPP1 & 0.883 & 0.734 & 0.932 \\
\hline & SUPP2 & 0.852 & & \\
\hline & SUPP3 & 0.880 & & \\
\hline & SUPP4 & 0.748 & & \\
\hline & SUPP5 & 0.911 & & \\
\hline & & & & \\
\hline
\end{tabular}

Next, the discriminant validity is assessed using HTMT technique developed by Henseler et al., (2015). Previous study has suggested 0.85 and 0.90 for HTMT construct thresholds to determine discriminant validity Henseler et al., (2015). As shown in Table 2, the results indicate that all constructs have passed the criterion of HTMT.90 (Gold et al., 2001) and the HTMT.85 (Kline, 2011). Furthermore, the HTMT inference result also shows that the confidence interval on any one of the structures does not show a value of 1 (Henseler et al., 2015).

Table 2: Discriminant Validity (HTMT .85 criterion)

\begin{tabular}{|l|l|l|l|l|}
\hline & $\begin{array}{l}\text { Perceived } \\
\text { Benefit }\end{array}$ & $\begin{array}{l}\text { Perceived } \\
\text { Cost }\end{array}$ & $\begin{array}{l}\text { Stakeholders' } \\
\text { Involvement }\end{array}$ & $\begin{array}{l}\text { Support for CBE } \\
\text { Development }\end{array}$ \\
\hline Perceived Benefit & & & & \\
\hline Perceived Cost & 0.71 & & & \\
\hline Stakeholders' Involvement & 0.838 & 0.706 & & \\
\hline Support for CBE Development & 0.61 & 0.592 & 0.681 & \\
\hline
\end{tabular}




\section{Assessment of the Structural Model}

The structural model for CBE support was evaluated in the second phase of analysis. To evaluate the structural model, it is necessary to make sure that the structural model does not have a problem of lateral collinearity. Although the criteria of discriminant validity (vertical collinearity) are met, the issue of lateral collinearity (predictor - criterion collinearity) can sometimes mislead the findings in a stealth manner because it can cover the strong causal impact of the model (Kock \& Lynn, 2012). This happens when the same construct is measured by two variables hypothesizing to be causally related. The lateral collinearity test result is presented in Table 3 below. For the other independent variables, all the internal VIF values (Stakeholders' Involvement). The lateral multicollinearity needs to be examined is less than 5, indicating that lateral multicollinearity is not an issue in this study (Hair et al., 2017).

Table 3: Lateral Collinearity Assessment

\begin{tabular}{|l|l|l|l|l|}
\hline & $\begin{array}{l}\text { Perceived } \\
\text { Benefit }\end{array}$ & $\begin{array}{l}\text { Perceived } \\
\text { Cost }\end{array}$ & $\begin{array}{l}\text { Stakeholders' } \\
\text { Involvement }\end{array}$ & $\begin{array}{l}\text { Support for CBE } \\
\text { Development }\end{array}$ \\
\hline Perceived Benefit & & & & 1.787 \\
\hline Perceived Cost & & & & 1.787 \\
\hline Stakeholders' Involvement & 1 & 1 & & \\
\hline Support for CBE Development & & & & \\
\hline
\end{tabular}

In this paper, between the constructs, four direct hypotheses are developed. Using the bootstrapping function, $\mathrm{t}$ - statistics for all paths are shown to test the significant level. Drawn from the result of path coefficient in Table 4, all four constructs were significant at $5 \%$ level where the t-value $\geq 1.645$. The results show stakeholders' involvement is positively related on perceived benefit of MHC stakeholders. Thus, H1 is supported. Next, the construct of stakeholders' involvement is negatively related on perceived cost of MHC stakeholders. Therefore, $\mathrm{H} 2$ is supported. Subsequently, the result of the effect of perceived benefit and perceived cost on supporting in CBE Development indicates perceived benefit is positively related to supporting in CBE development while perceived cost is negatively related to supporting in CBE development in rural MHC. This result supports $\mathrm{H} 3$ and $\mathrm{H} 4$ of this study. The research framework based on the determinants discussed in the MHC is shown in Figure 1. 


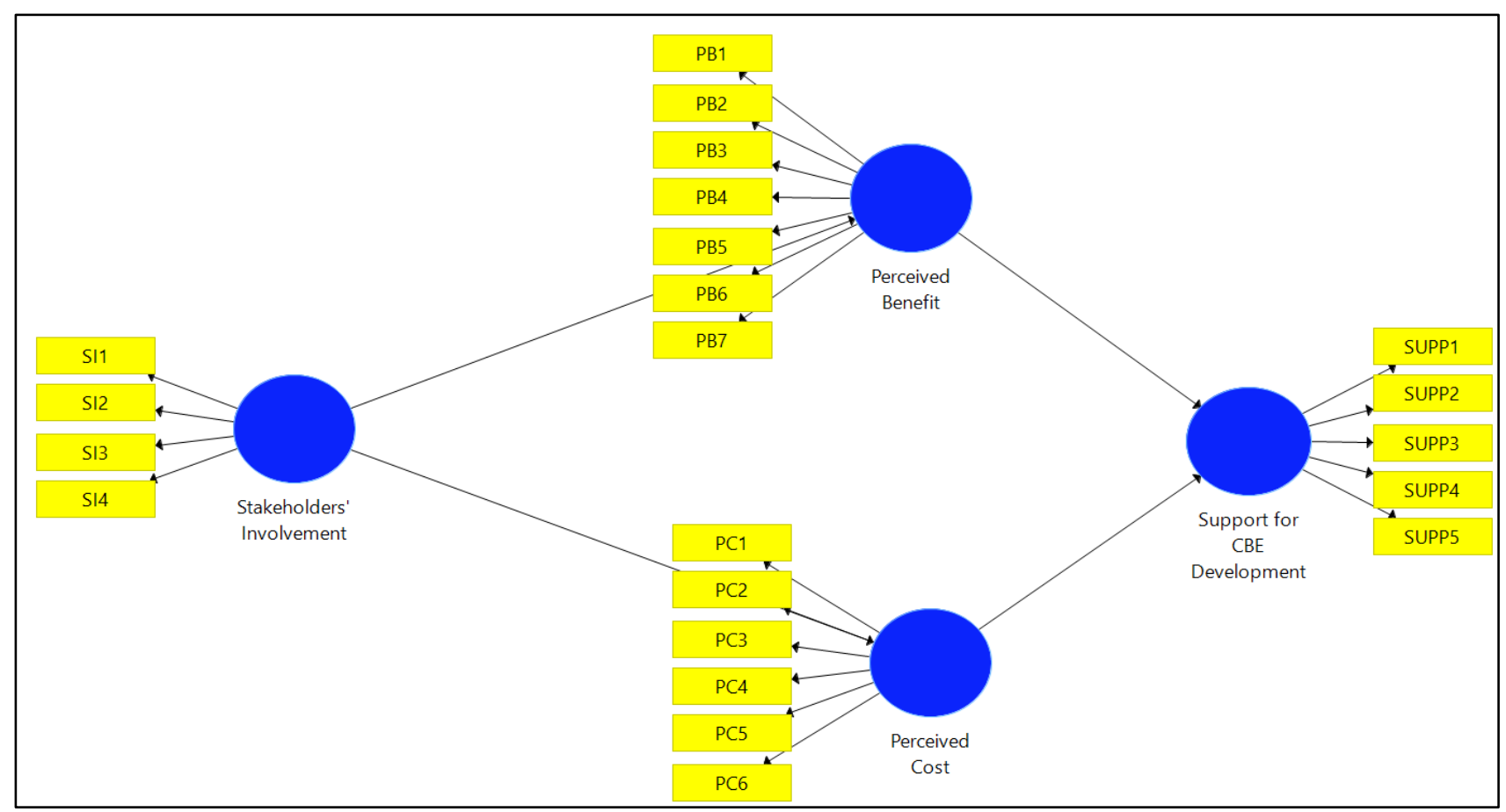

Notes: SI: Stakeholders Involvement; PB: Perceived Benefit; PC: Perceived Cost; SUPP: Support of CBE Development;

Figure 1: Research Framework of the Study

Table 4: Hypothesis Testing

\begin{tabular}{|l|l|l|l|l|l|}
\hline Hypothesis & $\begin{array}{l}\text { Original } \\
\text { Sample }\end{array}$ & $\begin{array}{l}\text { Sample } \\
\text { Mean }\end{array}$ & $\begin{array}{l}\text { Standard } \\
\text { Deviation }\end{array}$ & T Statistics & P Values \\
\hline $\begin{array}{l}\text { HI: Stakeholders' Involvement -> } \\
\text { Perceived Benefit_ }\end{array}$ & 0.702 & 0.691 & 0.069 & 10.218 & 0.00 \\
\hline $\begin{array}{l}\text { H2: Stakeholders' Involvement - } \\
\text { > Perceived Cost_- }\end{array}$ & -0.601 & -0.603 & 0.055 & 11.01 & 0.00 \\
\hline $\begin{array}{l}\text { H3: Perceived Benefit -> Support } \\
\text { for CBE Development }\end{array}$ & 0.367 & 0.362 & 0.071 & 5.189 & 0.00 \\
\hline $\begin{array}{l}\text { H4: Perceived Cost -> Support } \\
\text { for CBE Development }\end{array}$ & -0.317 & -0.327 & 0.076 & 4.2 & 0.00 \\
\hline
\end{tabular}

\section{Overall Path Coefficient}

Next, the assessment of coefficient of Determination $\left(\mathrm{R}^{2}\right)$, effect sizes $\left(f^{2}\right)$ and predictive relevance $\left(\mathrm{Q}^{2}\right)$ are shown in Table 5. According to Sullivan and Feinn (2012), p-value can only tell the reader if an effect exists but does not uncover the effect size. Both substantive meaning (effect size) and statistical significance ( $\mathrm{p}$ - value) are essential results for reporting when interpreting results. Based on Hair et al. (2017) the change in the $\mathrm{R}^{2}$ should also be evaluated and investigated to determine that whether the excluded independent variables have a significant impact on the dependent variables. Stakeholders' involvement explaining $49.3 \%$ of the variance of perceived benefit. The $\mathrm{R}^{2}$ value of 0.493 is above the 0.26 value as suggested by Cohen (1988) which indicated a substantial model that shown in Table 8. For the perceived cost, stakeholders' involvement, 
explaining $36.2 \%$. The $\mathrm{R}^{2}$ value of 0.362 is above the 0.26 value as suggested by Cohen (1988) which indicated a substantial model. Perceived benefit and perceived cost explaining $39 \%$ of the variance in supporting in CBE development. The $\mathrm{R}^{2}$ value of 0.39 is above the 0.26 value as suggested by Cohen (1988) indicated the results is a substantial model.

This study used Cohen (1988) guidelines to measure the effect size (f2), the values of $0.02,0.15$ and 0.35 respectively represent small, medium and large effects. From Table 8, it indicates that the effect size of stakeholders' involvement which are 0.97 and 0.567 has a large effect in producing the $\mathrm{R}^{2}$ for perceived benefit and perceived cost. Perceived benefit $(0.123)$ and perceived cost $(0.092)$ also have a small effect in producing the $\mathrm{R}^{2}$ for support for CBE development. Moreover, using the blindfolding procedure, the model's predictive relevance is examined. If the Q2 value exceeds 0, the model shows predictive relevance for certain dependent variables. (Hair et al., 2017; Fornell \& Cha, 1994). All the four $\mathrm{Q}^{2}$ values for perceived benefit $(0.493)$, perceived cost (0.362) and support for CBE development (0.39) are more than 0 , indicating that the model has sufficient predictive relevance.

\section{Table 5: Assessment level of Coefficient of Determination $\left(R^{2}\right)$, Effect size $\left(f^{2}\right)$ and Predictive Relevance $\left(\mathbf{Q}^{2}\right)$}

\begin{tabular}{|l|l|l|l|l|}
\hline Hypothesis & Relationship & $\mathrm{R}^{2}$ & $\mathrm{f}^{2}$ & $\mathrm{Q}^{2}$ \\
\hline Hypothesis 1 & $\mathrm{SI} \rightarrow$ PB & 0.493 & 0.97 & 0.329 \\
\hline Hypothesis 2 & SI $\rightarrow$ PC & 0.362 & 0.567 & 0.176 \\
\hline Hypothesis 7 & PB $\rightarrow$ SUPP & 0.39 & 0.123 & 0.257 \\
\hline Hypothesis 8 & PC $\rightarrow$ SUPP & & 0.092 & \\
\hline
\end{tabular}

\section{Discussion}

The aim of conducting this study was to use the theory of social exchange to test a model that explains stakeholder involvements' and perception to support CBE development in rural MHC, Kubang Kerian. The results indicate that stakeholders who have perceived more benefit of community ecotourism tend to support CBE development. These findings are in line with past studies using social exchange theory, which confirmed a positive effect of positive perception of residents' (perceived benefit) on supporting tourism development (Andereck et al., 2005; Choi and Sirakaya, 2006; Gursoy et al., 2002; Ko and Stewart, 2002; Wang and Pfister, 2008; Látková and Vogt, 2012). Stakeholders-related MHC are significantly more involved in the development of community ecotourism and is subsequently more aware of the effect of CBE on sites, which leads to more development support for those with positive perceptions. Moreover, MHC is surrounding with tropical greenery, hosting many cultural activities offered including handicraft-making, cooking lessons, traditional games and watch cultural performances such as the shadow play and Kelantanese traditional dance. Therefore, CBE development helps local communities to facilitate their rich culture, helps preserve local cultures by promoting cultural activities and enhances the pride of residents in their culture (Gursoy et al., 2002; Jaafar et al., 2015; Kim, 2013). On the other hand, stakeholders who have perceived more negative (perceived cost) of community ecotourism would oppose CBE development. The current result also consistent with previous studies that have identified negative effect for negative perception towards supporting tourism development in rural 
context (Látková and Vogt, 2012; Nicholas et al., 2009; Rasoolimanesh et al., 2015; Walpole and Goodwin, 2001; Wang and Pfister, 2008).

Furthermore, the importance of the findings emphasized a direct positive relationship of stakeholder's involvement towards support for CBE development in the rural context MHC. The result shows that stakeholders that were more engaged in the local community planning process for ecotourism development may have been more aware of possible benefits of CBE. These results show that increase in stakeholder involvement would help them understand better about benefit of tourism and have positive perception in line with previous studies findings' (Almeida-García et al., 2016; Andereck and Nyaupane,2011; Látková and Vogt,2012; Nicholas et al.,2009; Tosun 2002). However, a negative relationship was also found between stakeholders' negative perceptions and stakeholders' involvement. This finding is consistent with previous literature where it is expected that negative perceptions will discourage community engagement (Gursoy et al., 2002).

\section{Conclusions}

This study may assist local decision makers, government planners, protected areas authorities and tourism developers and promoters in identifying concerns and issues for stakeholders in developing and implementing appropriate policies and actions (Byrd, 2007; De Lopez, 2001; Weladji et al., 2003). Also, MHC destination need a strategic planning due to the interdependence in management and conservation of shared resources of multiple stakeholders (Byrd and Cardenas, 2006; Schoon, 2007). Therefore, the important to take account to understand the perspective of all parties involved in the ecotourism development and planning issues within their areas so that both parties can play a leading role (Parker and Khare, 2005; Stem et al., 2003).One major restriction of this study, however, is that each site in this study experienced different levels of development of CBE. Future studies should aim at comparing stakeholders' locally owned business and cooperative contexts that have different context of CBE development. Comparison of models of different contexts will not only enable them to be more advanced and refined but will also enable to includes other factors of stakeholders' perceptions (Sharpley, 2014).

The contribution is made more significant by the fact that we included different stakeholder local authorities, government agencies, businesses, universities, local communities, and visitor must work together in planning and regulating tourism development in the developing world as there being a limited research appearing in the literature (Ali et al.2017). In addition, the findings of the study have some crucial practical implications for the authorities in charge of rural MHC management in Kelantan. Our results underscore the importance of stakeholders' perceptions on their support for and participation in tourism development in rural destination. Local authorities should therefore seek to improve the positive impacts of tourism and stakeholders ' perceptions of these impacts; they should also seek to mitigate the negative impacts of CBE development.

\section{References}

Ali, F., Hussain, K., Nair, V., \& Nair, P. K. (2017). Stakeholders' perceptions \& attitudes towards tourism development in a mature destination. Turizam: međunarodni znanstveno-stručni časopis, 65(2), 173-186. 
Almeida-García, F., Peláez-Fernández, M. Á., Balbuena-Vázquez, A., \& Cortés-Macias, R. (2016). Residents' perceptions of tourism development in Benalmádena (Spain). Tourism Management, 54, 259-274.

Andereck, K. L., Valentine, K. M., Knopf, R. C., \& Vogt, C. A. (2005). Residents' perceptions of community tourism impacts. Annals of Tourism Research, 32(4) 1056-1076.

Andereck, K. L., \& Nyaupane, G. P. (2011). Exploring the Nature of Tourism and Quality of Life Perceptions among Residents, 50(3) 248-260. Journal of Travel Research.

Ap, J. (1992). Residents' perceptions on tourism impacts. Annals of tourism Research, 19(4), 665690.

Aref, F., \& Ma'rof, R. (2008). Barriers to community participation toward tourism development in Shiraz, Iran. Pakistan Journal of Social Sciences, 5(9), 936-940.

Ashley, C., \& Garland, E. B. (1994). Promoting Community-Based Tourism Development: Why, What, and How? (Vol. 4). Directorate of Environmental Affairs, Ministry of Environment and Tourism.

Byrd, E. (2007). Stakeholders in sustainable tourism development and their roles: applying stakeholder theory to sustainable tourism development, Tourism Review, 62(2), 6-13.

Byrd, E. T., \& Cardenas, D. A. (2006, March). Elements of stakeholder support for tourism in rural communities: The case study of eastern North Carolina. Southeastern Travel \& Tourism Research Association Research symposium. Sarasota, Florida.

Canadian Universities Consortium (2000), A Manual for Monitoring Community Tourism Development, Canadian Universities Consortium, Toronto.

Chin, W. W. (2010). How to Write Up and Report PLS Analyses. In Handbook of Partial Least Squares, (pp.655-690). Berlin, Heidelberg: Springer Berlin Heidelberg.

Choi, H. S. C., \& Sirakaya, E. (2006). Sustainability indicators for managing community tourism. Tourism Management, 27(6) 1274-1289.

Claiborne, P. (2010). Community Participation in Tourism Development and the Value of Social Capital-the case of Bastimentos, Bocas del Toro, Panamá.

Cohen, J. (1988). Statistical power analysis for the behavioral sciences. Statistical Power Analysis for the Behavioral Sciences.

De Lopez, T. T. (2001). Stakeholder management for conservation projects: A case study of Ream National Park, Cambodia. Environmental Management, 28(1) 47-60.

Fornell, C., \& Cha, J. (1994). Partial Least Squares. In B. R. P (Ed.), Advanced Methods of Marketing Research (Vol. 6446, pp. 52-78). Cambridge, MA: Cambridge, MA.

Garrod, B. (2003). Local Participation in the Planning and Management of Ecotourism: A Revised Model Approach. Journal of Ecotourism, 2(1), 33-53.

Gold, A. H., Malhotra, A., \& Segars, A. H. (2001). Knowledge management: an organizational capabilities perspective. Journal of Management Information Systems, 18(1), 185-214.

Gursoy, D., Jurowski, C., \& Uysal, M. (2002). Resident attitudes: A structural modeling approach. Annals of tourism research, 29(1), 79-105.

Gursoy, D., \& Rutherford, D. G. (2004). Host attitudes toward tourism: An improved structural model. Annals of Tourism Research, 31(3), 495-516.

Hair, J. F., Ringle, C. M., \& Sarstedt, M. (2011). PLS-SEM: Indeed, a Silver Bullet. The Journal of Marketing Theory and Practice, 19(2), 139-152. https://doi.org/10.2753/MTP1069667919020. 
Hair, J. F., Sarstedt, J. M., Hopkins, L., \& G. Kuppelwieser, V. (2014). Partial least squares structural equation modeling (PLS-SEM) An emerging tool in business research. European Business Review, 26(2), 106-121.

Hair, J., Hult, G., Ringle, C., \& Sarstedt, M. (2017). A primer on partial least squares structural equations modeling (PLS-SEM) (2nd ed.). Los Angeles, CA: SAGE.

Haobin Ye, B., Qiu Zhang, H., Huawen Shen, J., \& Goh, C. (2014). Does social identity affect residents' attitude toward tourism development? International Journal of Contemporary Hospitality Management, 26(6), 907-929.

Henseler, J., Ringle, C. M., \& Sarstedt, M. (2015). A new criterion for assessing discriminant validity in Variance-based Structural Equation Modeling. Journal of the Academy of Marketing Science, 43(1), 115-135.

Jaafar, M., S. M. Noor, and S. M. Rasoolimanesh. (2015). "Perception of Young Local Residents toward Sustainable Conservation Programmes: A Case Study of the Lenggong World Cultural Heritage Site." Tourism Management 48:154-63.

Jim, C. Y., \& Xu, S. S. (2002). Stifled stakeholders and subdued participation: interpreting local responses toward Shimentai Nature Reserve in South China. Environmental Management, 30(3), 327-341.

Ko, D. W., \& Stewart, W. P. (2002). A structural equation model of residents' attitudes for tourism development. Tourism Management, 23(5), 521-530.

Kock, N., \& Lynn, G. S. (2012). Lateral Collinearity and Misleading Results in Variance-Based SEM: An Illustration and Recommendations. Journal of the Association for Information Systems, 13(7), 546-580.

Kline, R. B. (2011). Principles and practice of structural equation modeling. New York: Guilford Press.

Lai, P. H., \& Nepal, S. K. (2006). Local perspectives of ecotourism development in Tawushan Nature Reserve, Taiwan. Tourism Management, 27(6), 1117-1129.

Látková, P., \& Vogt, C. A. (2012). Residents' attitudes toward existing and future tourism development in rural communities. Journal of Travel Research, 51(1), 50-67.

Moswete, N. N. (2009). Stakeholder perspectives on the potential for community-based ecotourism development and support for the Kgalagadi Transfrontier Park in Botswana. ProQuest Dissertations and Theses, 293

Nicholas, L., B. Thapa, and Y. Ko. (2009). “Residents' Perspectives of a World Heritage Site: The Pitons Management Area, St. Lucia.” Annals of Tourism Research 36 (3): 390-412.

Nunkoo, R., \& Ramkissoon, H. (2011). Developing a community support model for tourism. Annals of Tourism Research, 38(3), 964-988.

Lepp, A. (2008). Attitudes towards initial tourism development in a community with no prior tourism experience: The case of Bigodi, Uganda. Journal of Sustainable Tourism, 16(1), 522.

Nunkoo, R., \& Ramkissoon, H. (2011). Developing a community support model for tourism. Annals of Tourism Research, 38(3), 964-988.

Parker, S., \& Khare, A. (2005). Understanding success factors for ensuring sustainability in ecotourism development in southern Africa. Journal of Ecotourism, 4(1), 32-46.

Rasoolimanesh, S. M., Jaafar, M., Kock, N., \& Ramayah, T. (2015). A revised framework of social exchange theory to investigate the factors influencing residents' perceptions. Tourism Management Perspectives. 
Rasoolimanesh, S. M., Roldan, J. L., Jaafar, M., \& Ramayah, T. (2016). Factors Influencing Residents Perceptions toward Tourism Development: Differences across Rural and Urban World Heritage Sites. Journal of Travel Research, 1-16.

Rasoolimanesh, S. M., Ringle, C. M., Jaafar, M., \& Ramayah, T. (2017). Urban vs. rural destinations: Residents' perceptions, community participation and support for tourism development. Tourism Management, 60, 147-158.

Saito, H., \& Ruhanen, L. (2017). Power in tourism stakeholder collaborations: Power types and power holders. Journal of Hospitality and Tourism Management, 31, 189-196.

Schoon, M. L. (2007). Building Robustness to Disturbance: Governance in Southern African Peace Parks. School of Public and Environmental Affairs Indiana University, Canada.

Sharpley, R., \& Telfer, D. J. (2008). Tourism and development in the developing world. London: Routledg

Sharpley, R. (2014). Host perceptions of tourism: A review of the research. Tourism Management,42, 37-49

Stem, C. J., Lassoie, J. P., Lee, D. R., Deshler, D. D., \& Schelhas, J. W. (2003). Community participation in ecotourism benefits: The link to conservation practices and perspectives. Society \&Natural Resources, 16(5), 387-413.

Sullivan, G. M., \& Feinn, R. (2012). Using Effect Size - or Why the P Value Is Not Enough. Journal of Graduate Medical Education, 4(3), 279-82.

(The) Mountain Institute (2000), Community Based Tourism for Conservation and Development:A Resource Kit, The Mountain Institute, Kathmandu.

Tosun, C. (2002). Host perceptions of impacts: A comparative tourism study. Annals of Tourism Research, 29(1), 231-253. http://dx.doi.org/10.1016/s0160-7383(01) 00039-1.

Tsaur, S. H., Lin, Y. C., \& Lin, J. H. (2006). Evaluating ecotourism sustainability from the integrated perspective of resource, community and tourism. Tourism management, 27(4), 640-653.

Walpole, M. J., \& Goodwin, H. J. (2001). Local attitudes towards conservation and tourism around Komodo National Park, Indonesia. Environmental Conservation, 28(2), 160-166.

Wang, Y., \& Pfister, R. E. (2008). Residents' Attitudes Toward Tourism and Perceived Personal Benefits in a Rural Community. Journal of Travel Research, 47(1), 84-93.

Wanga, J. O., Hayombe, P. O., Agong, S. G., \& Mossberg, L. (2014). Stakeholder Involvement in Tourism Destination Development: A Case of Dunga Beach and Wetland, Kisumu County, Kenya. Journal of Arts and Humanities, 3(8), 13-27.

Weladji, R. B., Moe, S. R., \& Vedeld, P (2003). Stakeholder attitudes towards wildlife policy and Benoue wildlife conservation area, north Cameroon. Environmental conservation, 30(4),34-343

Yoon, Y., Gursoy, D., \& Chen, J. S. (2001). Validating a tourism development theory with structural equation modeling. Tourism Management, 22(4), 363-372. https://doi.org/10.1016/S0261-5177(00)00062-5.

Zhang, L., Homestay, L., \& Ecolodge, W. (2009). Lijiang Xintuo Ecotourism Company. Northwest Yunnan, interviewed on, 13. 